\section{Effect of chitosan and silicon oxide treatments on postharvest Valencia Late (Citrus $\times$ sinensis) fruits}

\author{
Beltrán $\mathrm{R}^{1 *}$, Otesinova $\mathrm{L}^{1}$, Cebrián $\mathrm{N}^{1}$, Zornoza $\mathrm{C}^{1}$, Breijo $\mathrm{F}^{1}$, \\ Reig $\mathbf{J}^{2}$, Garmendia $\mathrm{A}^{3}$ and Merle $\mathrm{H}^{1}$ \\ ${ }^{1}$ Department of Agroforestry Ecosystems, Valencia Polytechnic University, 46022 Valencia, Spain \\ ${ }^{2}$ Cavanilles Institute of Biodiversity and Evolutionary Biology, University of Valencia, 46010 \\ Valencia, Spain \\ ${ }^{3}$ Mediterranean Agroforestry Institute, Valencia Polytechnic University, 46022 Valencia, Spain
}

\section{Abstract}

The efficacy of chitosan and silicon oxide to prevent postharvest weight loss and fungi infection in 'Valencia Late' oranges was tested. Three silicon oxide concentrations $(0.1 \%, 0.2 \%, 1 \%)$ were applied as preharvest treatments. Chitosan treatments were performed at the same concentrations in postharvest fruit. Preharvest applications were carried out by tractor spraying, while fruit were submerged for 30 seconds in baths with the chitosan concentrations in the postharvest applications. In both cases, a positive control (water treatment) and negative control (fungicide) were included. Treated fruit were stored in a chamber to simulate commercial storage conditions $\left(4^{\circ} \mathrm{C}, 90 \% \mathrm{RH}\right)$ for 9 weeks. After this time, the weight loss and damage caused by fungi due to natural infection were evaluated. Both silicon oxide and chitosan applications were effective in controlling natural infection by Penicillium species but had no positive effect on weight loss.

\section{More Information}

*Address for Correspondence: Roberto Beltrán, Department of Agroforestry Ecosystems, Valencia Polytechnic University, 46022 Valencia, Spain, Email: robelmar74@gmail.com

Submitted: September 21, 2021

Approved: October 05, 2021

Published: October 06, 2021

How to cite this article: Beltrán R, Otesinova L, Cebrián N, Zornoza C, Breijo F, et al, Garmendia A3 and Merle H1. Effect of chitosan and silicon oxide treatments on postharvest Valencia Late (Citrus $\times$ sinensis) fruits. J Plant Sci Phytopathol. 2021; 5: 065-071.

DOI: 10.29328/journal.jpsp.1001063

ORCiD: orcid.org/0000-0001-9808-8335

Copyright: ๑ 2021 Beltrán R, et al. This is an open access article distributed under the Creative Commons Attribution License, which permits unrestricted use, distribution, and reproduction in any medium, provided the original work is properly cited.

Keywords: Citrus; Oranges; Fruit disease; Penicillium digitatum; Penicillium italicum; Weight Ioss; Chitosan; Silicon oxide; Mancozeb; Imazalil

Check for updates

OPEN ACCESS

\section{Introduction}

Citrus fruit production has increased worldwide since the past decade [1]. One of the main problems that citrus distribution chains face is the appearance of postharvest diseases, which can sometimes imply up to $80 \%$ harvest losses [2]. Penicillium digitatum (Pers.:Fr.) Sacc and Penicillium italicum Wehmer are the most economically important postharvest citrus fruit diseases in the main production areas $[3,4]$. Other fungi that can affect postharvest citrus fruit are Botrytis cinerea Pers ex Fr [5] and Geotrichum candidum Link ex Pers [6]. In addition, weight loss due to respiration and evaporation through skin [7], as well as chilling injury and peel pitting characterized by the collapse of epidermal and subepidermal cells on fruit surfaces, can also cause significant losses [8].

Therefore, the use of several products in pre- and postharvest applications has been studied to improve shelflife parameters, and the effect of chitosan on several fruit and vegetables has been reported $[9,10]$. Chitosan stimulates plant defenses against postharvest pathogens and interferes with fungal growth [11]. It is especially effective in improving postharvest characteristics in grape [12], guava [13], Luffa cylindrica (L.) M. Roem [14], strawberry [15] and tomato [16]. Several studies have pointed out its efficacy in prolonging the shelf life of citrus fruit, such as oranges (Citrus $\times$ sinensis (L.) Osbeck) 'Fortune' and 'Valencia' [11] and 'Navel' [17], in Citrus tankan Hayata [5], mandarins (Citrus reticulata Blanco) 'Or' and 'Mor', and in grapefruit (Citrus paradisi Macf.) 'Star Ruby' [18]. Chitosan effectiveness has been found in both postharvest treatments and in vitro experiments against P. digitatum [19] and P. italicum [20]. It is also efficient in preventing damage from other postharvest fungi diseases like Penicillium expansum Link and B. cinerea [17], Rhizopus stolonifer (Ehrenb.: Fr.) Vuill. and Aspergillus niger Tiegh [5]. Therefore, the safe use of chitosan in agriculture and food production has been reported [21].

Other compounds have been tested for similar purposes. Saberi, et al. [22] analyzed several coatings based on pea starch and guar gum in Valencia oranges. These new coatings lowered weight loss, firmness loss and respiration rates compared to commercial wax or uncoated fruit. Several metallic salts have been reported as being useful for reducing decay damage and preventing postharvest disease. He, et al. [23] evaluated the activity of zinc oxide nanoparticles against $P$. expansum and $B$. cinerea. Other metal oxides like 
$\mathrm{MgO}$ and $\mathrm{CaO}$ display antimicrobial activity against potential postharvest fungi like $A$. niger and $R$. stolonifer [24]. Sodium silicate is effective against Alternaria alternata (Fr.: Fr.) Keissl., Fusarium semitectum Berk. et Ravenel, Trichotecium roseum (Pers.: Fr.), P. expansum and Sclerotinia sclerotiorum (Lib.) De Bary in melon, pear and carrot [25-27]. A recent study has described a significant reduction in the postharvest deterioration of physico-chemical characteristics on mango after a preharvest potassium silicate treatment [28]. Likewise, several studies on citrus fruit have employed silicon salts. Liu, et al. [29] reported the antifungal effect of sodium silicate on controlling green mold in C. reticulata. Finally, treatments with $90 \mathrm{mM}$ of potassium silicate reduce the incidence of P. digitatum and P. italicum in 'Valencia' and 'Lanelate' oranges [30].

However, information about the specific effect of silicon oxide $\left(\mathrm{SiO}_{2}\right)$ on preventing postharvest infections of Penicillium species in stored citrus fruit is lacking. The low toxicity of this substance allows its use in agricultural products intended for human consumption [31]. Therefore, this study aims to test the efficacy of silicon oxide preharvest applications in Valencia Late (Citrus $\times$ sinensis) fruit, and to compare these treatments to chitosan postharvest applications.

\section{Materials and methods}

\section{Experimental site and plant material}

This study was carried out in a commercial orchard of 'Valencia Late' oranges located in Picassent, Valencia province, Spain (3921'51" N 032'24” W, 150 m altitude). This plot covers a total surface area of $21500 \mathrm{~m}^{2}$. Soil characteristics were calcareous sandy-clay loam with a pH of 8.06 and $5.2 \%$ limestone. The general site climate was Mediterranean xericoceanic, with long-term average annual rainfall of $440 \mathrm{~mm}$ and an average annual air temperature of $17.3^{\circ} \mathrm{C}$. The experiment was conducted on 30-year-old trees managed under standard cultural and drip irrigation conditions. The 'Valencia Late' orange trees were grafted onto the Carrizo citrange rootstock.

\section{Treatments}

The silicon treatments were carried out in the preharvest stage ( 1 week before harvest), while the chitosan ones were performed in the postharvest stage, on the fruit that did not undergo the silicon preharvest treatments. Both treatments consisted of three different product concentrations (low, medium, high), along with a negative control (fungicide treatment) and a positive control (treated only with water). For the silicon treatments, a commercial product based on monoxide silicon (formula) (SILIK ${ }^{\odot}$ ) was used. Concentrations were $0.1 \%$ ( $1 \mathrm{~g} / \mathrm{l}$; low silicon), $0.2 \%$ ( $2 \mathrm{~g} / \mathrm{l}$; medium silicon) and $1 \%$ (10 g/l; high silicon). The employed fungicide was mancozeb (NUFOZEBE ${ }^{\odot}$ ) at $0.25 \%$ (2.5 g/l). These five treatments were randomly distributed in a single row per treatment, with three border rows between them. Applications were applied by a sprayer tractor at constant 10 bar pressure, which delivered 2000 liters/ha. Thirty fruit per tree and three trees per treatment ( 90 fruit per treatment) were sampled for the silicon treatment evaluation.

The chitosan treatments were performed with a commercial product based on chitosan chlorhydrate $\left(\right.$ NANDA $\left.^{\odot}\right)$. Concentrations were $0.1 \%$ (1 g/l; low chitosan), $0.2 \%$ ( $2 \mathrm{~g} / \mathrm{l}$; medium chitosan) and 1\% (10 g/l; high chitosan). The used fungicide was imazalil (FRUITGARD ${ }^{\odot}$ ) at $0.25 \%$ (2.5 g/l). Treatments were applied to freshly harvested fruit that were randomly selected from the trees that received no previous treatment. These treatments were prepared in different containers and 30 fruit per treatment were submerged in solution for 30 seconds.

\section{Measurements}

After all the applications, the silicon- and chitosantreated fruit were weighed. Then fruit were distributed into boxes (15 fruit per box) and labeled ( 2 boxes per treatment) (Figure 1). Boxes were stored under commercial storage conditions, namely inside a chamber for 9 weeks at $4 \stackrel{\circ}{ } \mathrm{C}$ and $90 \%$ relative humidity (RH). Two evaluations were made at 6 and 9 weeks after being left in the chamber. During each evaluation, all the fruit were weighed to assess weight loss, whereas the presence of postharvest fungi caused by natural infection (Penicillium spp. and other species) was assessed. The employed infection damage scale ranged between 0 and 3 ( 0 : no symptoms; 1 : slight presence; 2 : medium presence, only in one fruit hemisphere; 3 : considerable presence, sporulation affecting more than one fruit hemisphere).

\section{Statistical analysis}

All the statistical analyses were performed with $\mathrm{R}$ [32] and RStudio [33]. Fisher's Exact Test for Count Data was used to compare damage frequencies, while Holm's correction method was followed for the post hoc analyses between treatments [34]. The initial fruit weights were not homogenous for the different treatments. Therefore, in order to homogenize the initial weights for all the treatments, fruit were analyzed separately in three size groups (small, medium and large fruit) using quantiles for $1 / 3$ and $2 / 3$. The fruit with the exact quantile weight were included in the medium-sized fruit class. Weight loss was measured individually for each

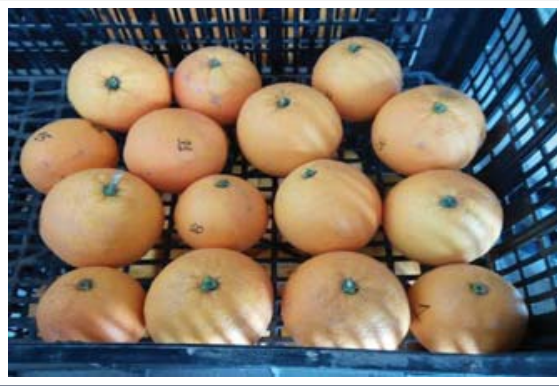

Figure 1: Valencia Late orange fruits before entering the storage chamber. 
fruit as the initial weight minus weight at 6 and 9 weeks. Both the ANOVA and Kruskal-Wallis tests, with Tukey post hoc test, were performed to assess differences between treatments.

\section{Results}

All the observed symptoms corresponded to the $P$. digitatum and P. italicum postharvest diseases by natural infection (Figure 2). As infection was not forced, the percentage of damaged fruit was low, even in the positive controls $(17.8 \%$ and $18.8 \%$ for the silicon oxide and chitosan positive controls, respectively). Positive effects to prevent Penicillium infection were observed at the two highest silicon concentrations (Figure 3). In this case, the medium (2 g/l) and high concentration (10 g/l) silicon oxide treatments showed the lowest frequency of damaged fruit after 9 storage weeks with significant differences with the positive control. Specifically, the medium silicon oxide concentration treatment showed three damaged fruit (3.3\%; Holm $p$ value $=0.024$ ) and the high concentration silicon oxide treatment only one (1.1\%; Holm $p$ value $=0.0014)$, while the positive control had 16 damaged fruit (17.8\%). Moreover, the observed number of damaged fruit was bigger in the negative control (fungicide) than in the three silicon oxide treatments. This indicates that all the silicon treatments, including the lowest concentration treatment ( $1 \mathrm{~g} / \mathrm{l})$, were effective in reducing the number of damaged fruit. In fact, the medium and high concentration silicon oxide treatments showed significant differences with fungicide treatment.

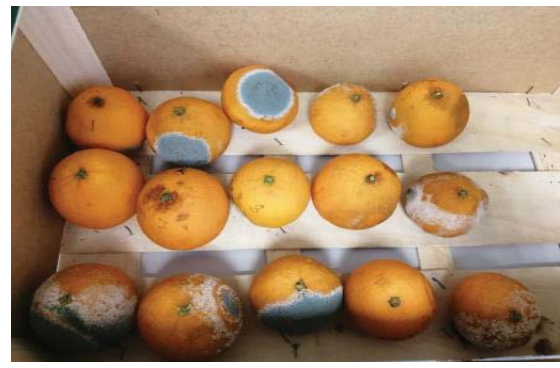

Figure 2: Valencia Late orange fruits affected with Penicillium digitatum (green mold) and Penicillium italicum (blue mold).

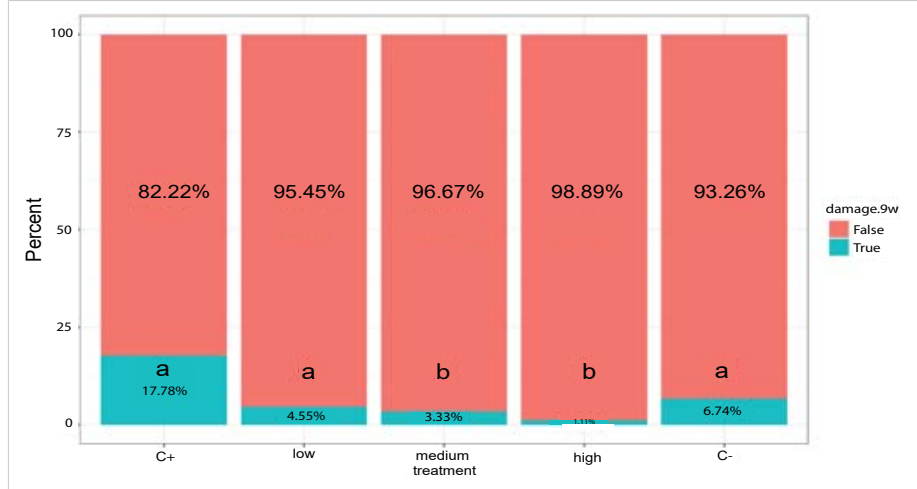

Figure 3: Damage frequencies of the silicon treatments after 9 storage weeks. 'False' refers to the fruit that did not show any symptoms. 'True' denotes the fruit that presented at least one symptom type on the considered 'damage scale'. Total Fisher test $p=2 e-04$
The chitosan treatments obtained similar results to the silicon oxide treatments in damaged fruit frequency terms (Figure 4). In this case, only the high concentration chitosan treatment showed significant differences compared to the positive control. Specifically, the positive control presented 17 damaged fruit (18.8\%), while only two damaged fruit were identified for the high concentration chitosan treatment, along with a significant difference $(2.2 \%$; Holm $p$ value = 0.00038). The frequency of the damaged fruit observed in the medium concentration chitosan treatment was similar to the fungicide treatment ( $6.7 \%$ and $7.8 \%$, respectively), and no significant differences were found. These two treatments did not show any significant differences with the positive control. The low concentration chitosan treatment showed no effect on preventing postharvest Penicillium infection, with a similar damaged fruit frequency as in the positive control (15.6\%).

No significant effect in weight loss was found for any treatment with the small, medium or large fruit (Tables 1-4). After 9 storage weeks, the highest and lowest weight losses were recorded in the positive (20.00 g) and the negative (18.54 g) controls with the silicon oxide treatments, but without any significant differences. The three silicon oxide treatments showed intermediate weight losses between the positive and negative controls (Figure 5). Similar tendencies were observed for the small (Table 1) and large fruit (Table 2).

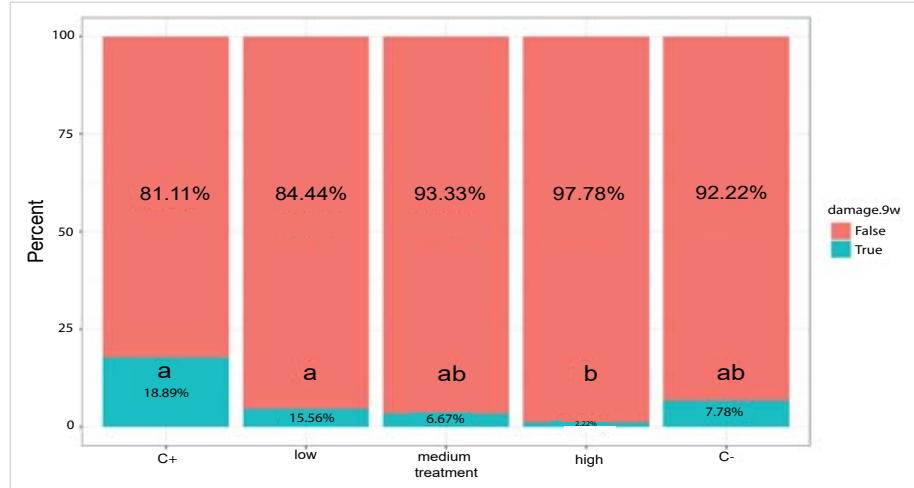

Figure 4: Damage frequencies of the chitosan treatments after 9 storage weeks. 'False' refers to the fruit that did not show any symptoms. 'True' denotes the fruit that displayed at least one symptom type on the considered 'damage scale'. Total Fisher test $p=0.00083$.

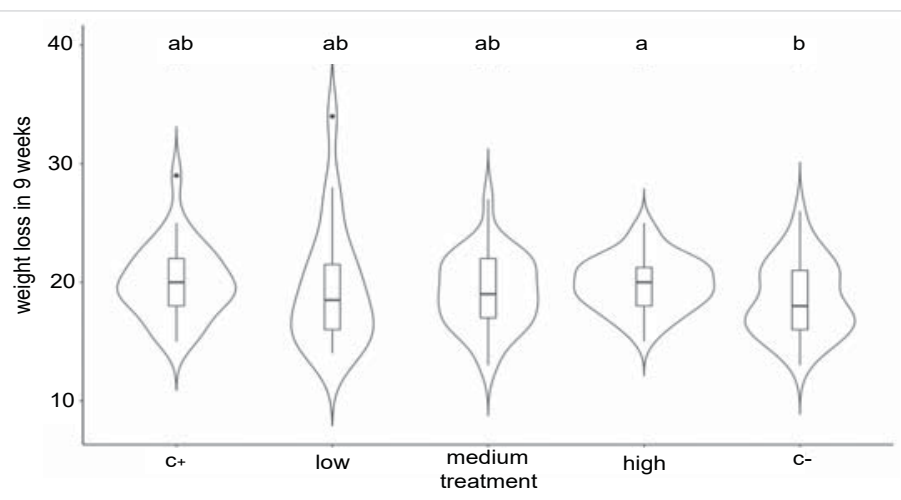

Figure 5: Violin plot of weight loss in the silicon treatments after 9 storage weeks. Different letters represent significant differences in the Kruskal-Wallis post hoc test $(\mathrm{KW})$ for alpha $=0.05$ 
Table 1: Effect of silicon treatments on weight loss in the small fruit after 9 storage weeks. The Kruskal-Wallis post hoc test (KW) letters should be used because the residuals did not meet the normality requirement for the ANOVA. Shapiro. $p=4.9 \mathrm{e}-06$. Different letters mean significant differences for alpha $=0.05$. $q$ stands for the studentized range in the Tukey test. All the treatments were run 1 week before harvest: C+, only water; low, silicon 1 g/l; medium, silicon 2 g/l; high, silicon 10 g/l; C-, mancozeb 2.5 g/l.

\begin{tabular}{|c|c|c|c|c|c|c|c|c|c|}
\hline Treatment & $\mathbf{N}$ & Mean & sd & se & skew & kurtosis & Shapiro & HSD & KW \\
\hline $\mathrm{C}+$ & 40 & 17.5250 & 3.81 & 0.60 & 1.78 & 5.77 & 0.00 & $a$ & $\mathrm{a}$ \\
\hline low & 47 & 17.1277 & 2.11 & 0.31 & 0.10 & -0.29 & 0.16 & a & $a$ \\
\hline medium & 24 & 17.8750 & 3.21 & 0.65 & 0.71 & 1.44 & 0.19 & a & $a$ \\
\hline high & 11 & 18.0000 & 1.95 & 0.59 & 0.59 & 0.58 & 0.83 & $a$ & $a$ \\
\hline C- & 22 & 17.9091 & 3.29 & 0.70 & 0.44 & -0.60 & 0.43 & $a$ & $a$ \\
\hline
\end{tabular}

Table 2: Effect of silicon treatments on weight loss in the large fruit after 9 storage weeks. The Kruskal-Wallis post hoc test (KW) letters should be used because the residuals did not meet the normality requirement for the ANOVA. Shapiro. $p=1.86 \mathrm{e}-09$. Different letters mean significant differences for alpha $=0.05$. $q$ stands for the studentized range in the Tukey test. All the treatments were run 1 week before harvest: C+, only water; low, silicon $1 \mathrm{~g} /$; medium, silicon $2 \mathrm{~g} /$; high, silicon $10 \mathrm{~g} / \mathrm{l}$; C-, mancozeb $2.5 \mathrm{~g} / \mathrm{l}$.

\begin{tabular}{|c|c|c|c|c|c|c|c|c|c|}
\hline Treatment & $\mathrm{N}$ & Mean & sd & se & skew & kurtosis & Shapiro & HSD & $\mathrm{KW}$ \\
\hline $\mathrm{C}+$ & 21 & 22.33 & 2.99 & 0.65 & 0.36 & -0.10 & 0.39 & a & $a b$ \\
\hline low & 21 & 23.71 & 4.19 & 0.91 & 0.12 & -0.72 & 0.63 & a & a \\
\hline medium & 37 & 21.97 & 2.94 & 0.48 & 1.01 & 1.50 & 0.01 & a & $a b$ \\
\hline high & 35 & 21.20 & 3.20 & 0.54 & 0.48 & 0.57 & 0.21 & a & $\mathrm{b}$ \\
\hline C- & 32 & 22.00 & 5.73 & 1.01 & 2.76 & 11.22 & 0.00 & $a$ & $b$ \\
\hline
\end{tabular}

Table 3: Effect of chitosan treatments on weight loss in the small fruit after 9 storage weeks. The Kruskal-Wallis post hoc test (KW) letters should be used because the residuals did not meet the normality requirement for the ANOVA. Shapiro.p $=1.25 \mathrm{e}-11$. Different letters mean significant differences for alpha $=0.05$. $q$ stands for the studentized range in the Tukey test. All the treatments were run on the same day after harvest: C+, only water; low, chitosan $1 \mathrm{~g} /$; medium, chitosan $2 \mathrm{~g} / \mathrm{l}$; high, chitosan $10 \mathrm{~g} / \mathrm{l}$; C-, imazalil $2.5 \mathrm{~g} / \mathrm{l}$.

\begin{tabular}{|c|c|c|c|c|c|c|c|c|c|}
\hline Treatment & $\mathbf{N}$ & Mean & sd & se & skew & kurtosis & Shapiro & HSD & KW \\
\hline $\mathrm{C}+$ & 26 & 16.85 & 8.17 & 1.60 & 3.36 & 14.18 & 0.00 & $a$ & $a b$ \\
\hline low & 31 & 16.65 & 4.70 & 0.84 & 0.55 & 0.01 & 0.26 & a & $a$ \\
\hline medium & 21 & 17.29 & 4.12 & 0.90 & 0.48 & 0.27 & 0.10 & a & a \\
\hline high & 43 & 14.60 & 4.08 & 0.62 & 0.83 & 0.44 & 0.02 & a & $\mathrm{b}$ \\
\hline C- & 26 & 17.19 & 4.30 & 0.84 & 1.83 & 6.61 & 0.00 & a & $a$ \\
\hline
\end{tabular}

Table 4: Effect of the chitosan treatments on weight loss in the large fruit after 9 storage weeks. The Kruskal-Wallis post hoc test (KW) letters should be used because the residuals did not meet the normality requirement for the ANOVA. Shapiro. $p=4.99 \mathrm{e}-10$. Different letters mean significant differences for alpha $=0.05$. $q$ stands for the studentized range in the Tukey test. All the treatments were run on the same day after harvest: $\mathrm{C}+$, only water; low, chitosan $1 \mathrm{~g} / \mathrm{l} ;$ medium, chitosan $2 \mathrm{~g} / \mathrm{l}$; high, chitosan 10 $\mathrm{g} / \mathrm{l}$; C-, imazalil $2.5 \mathrm{~g} / \mathrm{l}$.

\begin{tabular}{|c|c|c|c|c|c|c|c|c|c|}
\hline Treatment & $\mathbf{N}$ & Mean & sd & se & skew & kurtosis & Shapiro & HSD & KW \\
\hline $\mathrm{C}+$ & 29 & 21.62 & 7.05 & 1.31 & 2.76 & 10.38 & 0.00 & a & $a b$ \\
\hline low & 29 & 21.59 & 4.38 & 0.81 & 0.58 & -0.46 & 0.11 & a & $a$ \\
\hline medium & 41 & 19.44 & 4.60 & 0.72 & 1.16 & 1.53 & 0.01 & a & $b$ \\
\hline high & 20 & 20.10 & 3.02 & 0.68 & 1.10 & 0.08 & 0.00 & a & $a b$ \\
\hline C- & 28 & 21.21 & 4.17 & 0.79 & 0.74 & 0.44 & 0.22 & $a$ & $a$ \\
\hline
\end{tabular}

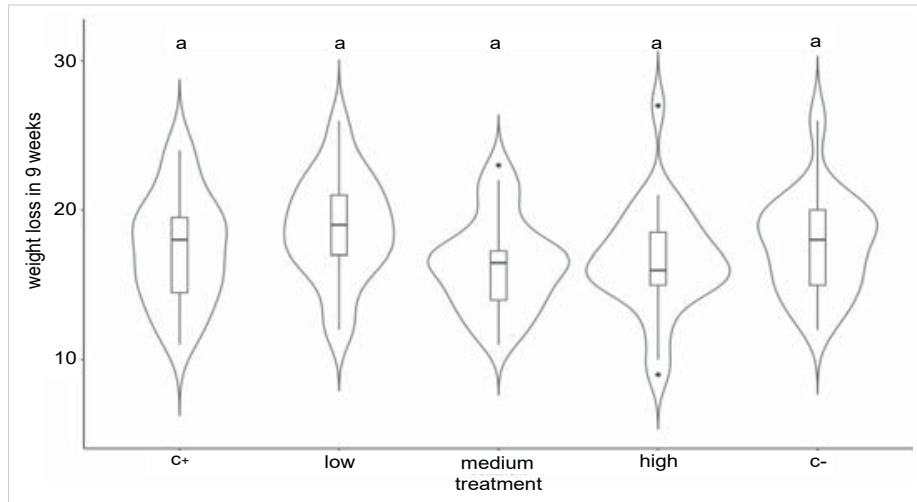

Figure 6: Violin plot of weight loss in the chitosan treatments after 9 storage weeks. Different letters represent significant differences in the Kruskal-Wallis post hoc test $(\mathrm{KW})$ for alpha $=0.05$

The weight loss of the small fruit was minor, but with a larger percentage of weight loss than for the large fruit. However, no significant differences between treatments were observed in any fruit group.

No significant differences in weight loss in the three chitosan treatments and the two controls after 9 storage weeks (Figure 6), or between the chitosan treatments and the control for the small (Table 3) and large (Table 4) fruit, were observed.

\section{Discussion}

The results showed less damage caused by the postharvest pathogens after the silicon oxide and chitosan treatments. The two postharvest disease species by natural infection (P. digitatum and P. italicum) found in this study are considered to be the most frequent postharvest fungi in the navel fruit group [17].

We observed a lower infection level in all the treatments, even in the positive control. This was probably due to: infection being natural and not inoculated; low storage temperatures $\left(4^{\circ} \mathrm{C}\right)$; a low inoculum level in the field that year. Other variables like variety ('Valencia Late') and fruit rind quality, which can vary annually, can influence the overall infection level. In any case, the highest chitosan concentration (1\%) 
came over as being better able to avoid natural postharvest Penicillium infections. This result agrees with similar studies conducted on 'Valencia' oranges stored at $4 \stackrel{\circ}{\circ} \mathrm{C}$ for 8 weeks, which checked the efficacy of postharvest chitosan treatment against natural Penicillium infection [35]. Other studies report the efficacy of these treatments at concentrations between 0.1 and 2\% [9]. The incidence of postharvest Penicillium species is generally higher when artificial inoculation is carried out [5] and Chien, et al. [10] recorded more than $40 \%$ infected fruit after a postharvest chitosan treatment and the subsequent Penicillium inoculation in citrus Tankan and 'Murcott' tangor, respectively. These studies were conducted under relatively warm storage conditions ( $24^{\circ} \mathrm{C}$ and $15^{\circ} \mathrm{C}$, respectively), which enhanced the growth and spread of postharvest disease. This would also explain the results obtained by Zeng, et al. [17], who reported a $P$. italicum incidence of up to $20 \%$ in navel orange fruit treated at the $2 \%$ chitosan concentration after 23 storage days at $20^{\circ} \mathrm{C}$.

To the best of our knowledge, this is the first report of the effect of silicon oxide preharvest applications on preventing postharvest diseases in citrus fruit. Therefore, silicon oxide could be considered a new citrus postharvest disease control method. In fact, we only found data about the antimicrobial effects of silicon oxide from the in vitro tests. García-Saucedo, et al. [36] did not detect any effect of the silicon oxide particles tested in vitro against yeast Saccharomyces cerevisiae Meyen ex E.C. Hansen. Likewise, no effect against fungus Candida albicans (Robin) Berkhout was observed in a similar experiment [37]. However, silicon compounds apart from silicon oxide have already been tested to prevent Penicillium spp. and other fungi infections Liu, et al. [29] reported the effect of sodium silicate on inhibiting $P$. digitatum growth on $C$. reticulata. These authors suggested that any silicon compound could have effects against fungal pathogens. Youssef, et al. [38] observed minor fruit decay in orange fruit after applying a preharvest sodium silicate treatment, and potassium silicate postharvest applications showed preventive and curative antifungal activity against green mold and blue mold [30]. Finally, a recent study discussed the characteristics of chitosan/silicate nanocomposites obtained by inserting chitosan chain into silicate interlayers and their possible uses to control $P$. digitatum on orange fruit [39]. For all these reasons, silicon oxide must be added to silicon-based compounds as an effective control method against postharvest diseases in citrus fruit.

No tested chitosan concentration was effective in preventing the fruit weight loss associated with long-term decay. Previous studies carried out on harvested chitosantreated fruit have reported less weight loss than controls. Perhaps chitosan application in a 30-second bath could be less effective than other types of postharvest treatments, such as applying a wax layer. This was the case of the study conducted by Hernández, et al. [35], who reported greater weight loss on orange fruit covered with chitosan compared to fruit covered with commercial wax. In contrast, several studies in which treatments consisted in immersing fruit for longer times and being left to dry report a positive effect even at low chitosan concentrations. Chien and Chou, [5] recorded minor weight loss in Tankan citrus fruit treated with $0.1 \%$ and $0.2 \%$ chitosan compared to the fungicide control, whereas Chien, et al. [10] observed less weight tangor fruit loss after a $0.1 \%$ chitosan treatment. In this study, not even the 1\% chitosan concentration was able to significantly reduce weight loss compared to the control.

Silicon oxide treatments are not effective in controlling weight loss. To date, several available studies have focused on other silicon compounds applied to both pre- and postharvest treatments. In these studies, silicon-based treatments achieved less weight loss than their controls. Bi, et al. [25] reported lower decay incidence and less decay severity in Hami melons (Cucumis melo L. var. inodorus Jacq.) after several postharvest sodium silicate treatments. After conducting experiments on Hami melons, the authors reported high solubility for the applied sodium silicate to explain their results. Perhaps our different silicon oxide solubility could hinder a layer from being formed on fruit. Weight loss reduction is related to greater water vapor resistance because of the hydrophobic characteristics of the film formed by the applied compounds [40]. As we applied silicon oxide in our preharvest treatments, the layer that would have covered fruit could have been lost before storage owing to unexpected factors like weather conditions. The silicon oxide effect on reducing Penicillium infections has been related to cell wall strengthening [41], which could increase their resistance to senescence. However, our work is the first weight loss study to be carried out after a preharvest silicon oxide application, and the results showed no effect.

In a recent study, Mohamed, et al. [28] reported reduced weight loss in mango after a preharvest potassium silicate application. These authors noted that the higher concentration chitosan and potassium silicate mixture led to less weight loss. Finally, it is likely that the silicon oxide concentration herein used did not suffice to cover fruit and to, therefore, confer the appropriate physical characteristics. The abovecited study suggested that the formation of a silicon layer to totally cover the fruit stomata was the main cause of reduced fruit respiration. So, it would be interesting to perform further studies at higher silicon oxide concentrations.

Although we did not observe an effect on weight loss, the results herein obtained with natural infection in 'Valencia Late' oranges indicated that the preharvest silicon oxide and chitosan treatments were effective in preventing Penicillium postharvest infection, and in subsequently improving harvested fruit quality. It would be advisable to carry out further studies by applying artificial $P$. digitatum and $P$. italicum infections or higher silicon oxide concentrations to acquire more conclusive data. 


\section{Conclusion}

Silicon oxide at $0.2 \%$ and $1 \%$ in a preharvest application to Valencia Late orange fruit was effective in preventing the natural infection of Penicillium species after 9 storage weeks. The three tested silicon oxide concentrations showed a lower damaged fruit incidence than the fungicide control. Likewise, the $1 \%$ chitosan concentration in the postharvest application tested under the same conditions was also effective in preventing Penicillium infection. However, the silicon oxide and chitosan treatments at the herein tested concentrations were not effective in preventing senescence-related fruit weight loss. Further studies are required to match the most appropriate concentration of silicon oxide applications to control postharvest disease and senescence-related weight loss.

\section{References}

1. FAO. Resource Database, Crops [WWW Document]. 2018. http://www.fao.org/faostat/en/\#data/

2. Liao HL, Alferez F, Burns JK. Assessment of blue light treatments on citrus postharvest diseases. Postharvest Biol Technol. 2013; 81: 81-88.

3. Palou L. Penicillium digitatum, Penicillium italicum (green mold, blue mold). In Postharvest Decay. 2013; 45-102.

4. Valencia-Chamorro SA, Pérez-Gago MB, Del Río MA, Palou L. Effect of Antifungal Hydroxypropyl Methylcellulose-Lipid Edible Composite Coatings on Penicillium Decay Development and Postharvest Quality of Cold-Stored "Ortanique" Mandarins. J Food Sci. 2010; 75: S418-S426. PubMed: https://pubmed.ncbi.nlm.nih.gov/21535515/

5. Chien PJ, Chou CC. Antifungal activity of chitosan and its application to control postharvest quality and fungal rotting of Tankan citrus fruit (Citrus tankan Hayata). J Sci Food Agricul. 2016; 86: 1964-1969.

6. Plaza P, Sanbruno A, Usall J, Lamarca N, Torres R, et al. Integration of curing treatments with degreening to control the main postharvest diseases of clementine mandarins. Postharvest Biol Technol. 2004; 34: 29-37.

7. Shiekh RA, Malik MA, Al-Thabaiti SA, Shiekh MA. Chitosan as a nove edible coating for fresh fruits. Food Sci Technol Res. 2013; 19: 139155.

8. Lafuente MT, Alférez F, Romero P. Postharvest ethylene conditioning as a tool to reduce quality loss of stored mature sweet oranges. Postharvest Biol Technol. 2014; 94: 104-111.

9. Bautista-Baños S, Hernández-Lauzardo AN, Velázquez-Del Valle MG Hernández-López M, Barka EA, et al. Chitosan as a potential natura compound to control pre and postharvest diseases of horticultural commodities. Crop Protection. 2006; 25: 108-118.

10. Chien PJ, Sheu F, Lin HR. Coating citrus (Murcott tangor) fruit with low molecular weight chitosan increases postharvest quality and shelf life. Food Chemistry. 2007; 100: 1160-1164.

11. Galed G, Fernández-Valle ME, Martínez A, Heras A. Application of MRI to monitor the process of ripening and decay in citrus treated with chitosan solutions. Magne Resona Imag. 2004; 22: 127-137.

12. Romanazzi G, Karabulut OA, Smilanick JL. Combination of chitosan and ethanol to control postharvest gray mold of table grapes. Postharvest Biol Technol. 2007; 45: 134-140.

13. Hong K, Xie J, Zhang L, Sun D, Gong D. Effects of chitosan coating on postharvest life and quality of guava (Psidium guajava L.) fruit during cold storage. Scientia Horticulturae. 2012; 144: 172-178.

14. Han C, Zuo J, Wang Q, Xu L, Zhai B, et al. Effects of chitosan coating on postharvest quality and shelf life of sponge gourd (Luffa cylindrica) during storage. Sci Horticultur. 2014; 166: 1-8.

15. Gol NB, Patel PR, Rao TR. Improvement of quality and shelf-life of strawberries with edible coatings enriched with chitosan. Postharvest Biol Technol. 2013; 85: 185-195.

16. El Ghaouth A, Ponnampalam R, Castaigne F, Arul J. Chitosan coating to extend the storage life of tomatoes. HortScience. 1992; 27: 1016-1018.

17. Zeng K, Deng Y, Ming J, Deng L. Induction of disease resistance and ROS metabolism in navel oranges by chitosan. Sci Horticultur. 2010; 126: 223-228.

18. Arnon H, Zaitsev Y, Porat R, Poverenov E. Effects of carboxymethyl cellulose and chitosan bilayer edible coating on postharvest quality of citrus fruit. Postharvest Biol Technol. 2014; 87: 21-26.

19. El Guilli M, Hamza A, Clément C, Ibriz M, Ait Barka E. Effectiveness of postharvest treatment with chitosan to control citrus green mold. Agriculture. 2016; 6: 12

20. Sánchez-González L, Cháfer M, Chiralt A, González-Martínez C Physical properties of edible chitosan films containing bergamot essential oil and their inhibitory action on Penicillium italicum. Carbohydrate Polymers. 2010; 82: 277-283.

21. Kean T, Thanou M. Biodegradation, biodistribution and toxicity of chitosan. Adv Drug Deliv Rev. 2010; 62: 3-11. PubMed: https://pubmed.ncbi.nlm.nih.gov/19800377/

22. Saberi B, Golding JB, Marques JR, Pristijono P, Chockchaisawasdee $S$, et al. Application of biocomposite edible coatings based on pea starch and guar gum on quality, storability and shelf life of 'Valencia' oranges. Postharvest Biol Technol. 2018; 137: 9-20.

23. He L, Liu Y, Mustapha A, Lin M. Antifungal activity of zinc oxide nanoparticles against Botrytis cinerea and Penicillium expansum. Microbiol Res. 2011; 166: 207-215.

PubMed: https://pubmed.ncbi.nlm.nih.gov/20630731/

24. Sawai J, Yoshikawa T. Quantitative evaluation of antifungal activity of metallic oxide powders ( $\mathrm{MgO}, \mathrm{CaO}$ and $\mathrm{ZnO})$ by an indirect conductimetric assay. J Appl Microbiol. 2004; 96: 803-809. PubMed: https://pubmed.ncbi.nlm.nih.gov/15012819/

25. Bi Y, Tian SP, Guo YR, Ge YH, Qin GZ. Sodium silicate reduces postharvest decay on Hami melons: induced resistance and fungistatic effects. Plant Dis. 2006; 90: 279-283

PubMed: https://pubmed.ncbi.nlm.nih.gov/30786549/

26. Guo Y, Liu L, Zhao J, Bi Y. Use of silicon oxide and sodium silicate for controlling Trichothecium roseum postharvest rot in Chinese cantaloupe (Cucumis melo L.). Int J Food Sci Technol. 2007; 42: 1012-1018.

27. Elsherbiny EA, Taher MA. Silicon induces resistance to postharvest rot of carrot caused by Sclerotinia sclerotiorum and the possible of defense mechanisms. Postharvest Biol Technol. 2018; 140: 11-17.

28. Mohamed MAA, El-khalek AFA, Elmehrat HG. Pre-harvest Potassium Silicate, Chitosan and calcium chloride Application Improves Mango Fruits (Zebda Cv.) Quality and Storability. Egyptian J Horticulture. 2017; 44: 17-32.

29. Liu J, Zong Y, Qin G, Li B, Tian S. Plasma membrane damage contributes to antifungal activity of silicon against Penicillium digitatum. Curr Microbiol. 2010; 61: 274-279.

PubMed: https://pubmed.ncbi.nlm.nih.gov/20195609/

30. Moscoso-Ramírez PA, Palou L. Preventive and curative activity of postharvest potassium silicate treatments to control green and blue molds on orange fruit. Eur J Plant Pathol. 2014; 138: 721-732.

31. Yun JW, Kim SH, You JR, Kim WH, Jang JJ, et al. Comparative toxicity of silicon dioxide, silver and iron oxide nanoparticles after repeated oral administration to rats. J Appl Toxicol. 2015; 35: 681-693. PubMed: https://pubmed.ncbi.nlm.nih.gov/25752675/

32. R Core Team. R: A Language and Environment for Statistical 
Computing. Vienna: R Foundation for Statistical Computing. 2017. https://www.R-proyect.org

33. RStudio Team. RStudio: Integrated Development for R. RStudio, Inc, Boston, MA. 2016. http://www.rstudio.com

34. Holm S. A Simple Sequentially Rejective Multiple Test Procedure. Scandinavian J Statist. 1979; 65-70.

35. Hernández JF, Ruiz JM, Félix AR. Efecto de recubrimiento con Quitosano y cera comercial en la calidad de naranja 'valencia' durante el almacenamiento. Revista Iberoamericana de Tecnología Postcosecha. 2011; 12: 164-174.

36. García-Saucedo C, Field JA, Otero-González L, Sierra-Álvarez R. Low toxicity of $\mathrm{HfO} 2, \mathrm{SiO} 2, \mathrm{Al} 2 \mathrm{O} 3$ and $\mathrm{CeO} 2$ nanoparticles to the yeast, Saccharomyces cerevisiae. J Hazard Materials. 2011; 192: 1572-1579. PubMed: https://pubmed.ncbi.nlm.nih.gov/21782338/

37. Karimiyan A, Najafzadeh H, Ghorbanpour M, Hekmati-Moghaddam $\mathrm{SH}$. Antifungal effect of magnesium oxide, zinc oxide, silicon oxide and copper oxide nanoparticles against Candida albicans. Zahedan J Res
Med Sci. 2015; 17: 19-23.

38. Youssef K, Ligorio A, Sanzani SM, Nigro F, Ippolito A. Control of storage diseases of citrus by pre-and postharvest application of salts. Postharvest Biol Technol. 2012; 72: 57-63.

39. Ruffo-Roberto S, Youssef K, Hashim AF, Ippolito A. Nanomaterials as alternative control means against postharvest diseases in fruit crops. Nanomaterials. 2019; 9: 1752

PubMed: https://pubmed.ncbi.nlm.nih.gov/31835458/

40. Sánchez-González L, Vargas $M$, González-Martínez C, Chiralt A, Chafer M. Use of essential oils in bioactive edible coatings: a review. Food Engineer Rev. 2011; 3: 1-16.

41. Epstein E. Silicon. Annu Rev Plant Physiol Plant Mol Biol. 1999; 50 641-664.

PubMed: https://pubmed.ncbi.nlm.nih.gov/15012222/

42. Li YH, Bi Y, Zhang HY, Ge YH, Liu J. Inhibiting effect of postharvest sodium silicate treatment on blue mould of pear (cv. Pingguoli). J Gansu Agri Univers. 2008; 6: 33. 